\title{
El Kant de Heidegger
}

\section{Heidegger's Kant}

\author{
0 Kant de \\ Heidegger
}

\section{Para citar este artículo}

Tillería Aqueveque, L. (2021). El Kant de Heidegger. Folios, (54). https:// doi.org/10.17227/folios.54-12234

Artículo recibido $05 \cdot 08 \cdot 2020$

Artículo aprobado $28 \cdot 01 \cdot 2021$

* Doctor en Filosofía de la Universidad de Chile. Profesor de la Universidad Tecnológica de Chile Inacap. Correo: leopoldo.tilleria@inacapmail.cl 


\title{
Resumen
}

Este artículo de reflexión sugiere algunas notas a la crítica que Heidegger hiciera a Kant en su célebre Kant y el problema de la metafísica de 1929. De esta forma, se discuten los alcances de la observación heideggeriana en cuanto a que en la deducción trascendental de su primera crítica, Kant habría retrocedido ante el descubrimiento de la imaginación como fundamento del conocimiento ontológico. Incorporando las recepciones de Žižek, Castoriadis y Martínez Marzoa, se corrobora que el mérito de Heidegger es reconocer que, en la deducción trascendental, Kant habría dudado entre la psicología y la lógica, al no haber visto ninguna tercera alternativa, terminando por descartar su apego a la subjetividad y optando por una versión lógica "al estilo escolástico". Finalmente, se conjetura que el retroceso del filósofo de Königsberg no fue ante el descubrimiento del fundamento, sino en realidad ante la posibilidad de una interpretación fenomenológica del mundo.

\author{
Palabras clave \\ crítica; filosofía; imaginación; metafísica; tiempo
}

\begin{abstract}
This reflection article suggests some notes to Heidegger's critique of Kant in his famous Kant and the problem of metaphysics of 1929. The scope of Heidegger's observation is discussed in that in the transcendental deduction of his first critique, Kant would have retreated before the discovery of the imagination as the foundation of ontological knowledge. Incorporating the receptions of Žižek, Castoriadis and Martínez Marzoa, it is corroborated that Heidegger's merit is to recognize that in the transcendental deduction Kant would have hesitated between psychology and logic, having not seen any third alternative, ending up discarding his attachment to subjectivity and opting for a logical version "scholastic style". Finally, it is conjectured that the retreat of the Königsberg philosopher was not before the discovery of the foundation, but actually in the face of the possibility of a phenomenological interpretation of the world.

\section{Keywords}

criticism; philosophy; imagination; metaphysics; time

0 artigo de reflexão sugere algumas notas à crítica de Heidegger sobre Kant em seu famoso Kant e o problema da metafísica de 1929. 0 escopo da observação de Heidegger é discutido na medida em que na dedução transcendental de sua primeira crítica Kant teria recuado antes da descoberta da imaginação como base do conhecimento ontológico. Incorporando as recepções de Žižek, Castoriadis e Martínez Marzoa, é corroborado que o mérito de Heidegger é reconhecer que na dedução transcendental Kant teria hesitado entre psicologia e lógica, não tendo visto nenhuma terceira alternativa, acabando descartando seu apego à subjetividade e optando por uma versão lógica "estilo escolástico". Finalmente, é suposto que a regressão do filósofo de Königsberg não foi antes da descoberta da fundação, mas na verdade diante da possibilidade de uma interpretação fenomenológica do mundo.
\end{abstract}

Abstract

\section{Resumo}

\section{Palavras chave}

crítica; filosofia; imaginação; metafísica; tempo 


\section{Introducción}

Pocos conceptos en la colosal arquitectura de la filosofía de Kant han sido objeto de tanta controversia como el de la imaginación. Por lo mismo, no entraré acá en un cuentagotas de los numerosos intérpretes que han visto su "propia" imaginación en la obra del filósofo de Königsberg, a tal punto que perfectamente cabría hablar hoy, por sí sola, de una "teoría" de la imaginación kantiana.

Gran parte de la controversia se debe al propio Kant, quien, en las dos ediciones de la Crítica de la razón pura $(\mathrm{CrP})$, presentó una imaginación con énfasis productivos distintos en su función de enlace entre sensibilidad y entendimiento. Reduciendo un poco los términos, digamos que la imaginación que Kant presenta en la edición A (1781) posee un fuerte sentido epistemológico, centrada literalmente en su función cognoscitiva. Escribe Kant (1998): "La síntesis es un mero efecto de la imaginación, una función anímicamente ciega, pero indispensable, sin la cual no tendríamos conocimiento alguno y de la cual, sin embargo, raras veces somos conscientes" (A 78). Para luego agregar: "La imaginación es también una facultad de síntesis a priori. Por ello la denominamos imaginación productiva" (A 123). En cambio, en la edición B (1787) Kant desdibuja el rol epistémico atribuido a la imaginación en la primera edición, y se lo asigna -en una redacción bastante dispersa- expresamente al entendimiento, restándole a aquella la sorpresiva autonomía con que la había presentado en su doctrina gnoseológica: "La combinación (conjunctio) de una variedad en general [...] es un acto de la espontaneidad de la facultad de representar. [...] esta facultad ha de llamarse entendimiento, para distinguirla de la sensibilidad" (Kant, 1998, B 130).

Fue Heidegger, en su Kant y el problema de la metafísica (1929), uno de los primeros en denominar retroceso a este giro en la deducción trascendental de la $C r P$. A su juicio, tal retroceso tiene que ver con que Kant se habría detenido ante el descubrimiento del papel central de la imaginación en el problema del conocimiento, el que habría significado virtualmente hacer pender de la fantasía todo el edificio de la racionalidad moderna. En todo caso, la depuración de la función de la imaginación trascendental que Kant aplica en la segunda edición tiene que ver fundamentalmente con una observación que hace Kant (1998) en su introducción a la primera crítica: "Como introducción o nota preliminar, solo parece necesario indicar que existen dos troncos del conocimiento humano, los cuales proceden acaso de una raíz común, pero desconocida para nosotros: la sensibilidad y el entendimiento" (A 15). El problema, tal como advierte Ferraris (1999), es que Kant no explica "ni aquí ni en otro lugar, cómo tiene lugar esta comunicación entre lo sensible y lo inteligible, y entre la pasividad y la actividad. Habla de ello como de un misterio depositado en las profundidades del alma humana" (p. 149).

Como es sabido, todo el libro de Heidegger sobre Kant gira en torno a esta "desconocida raíz común”. La interpretación del filósofo de Friburgo no deja dudas de que tal raíz es la imaginación trascendental: "La interpretación más originaria del fundamento establecido no solamente reveló que esta facultad intermediaria es el centro originariamente unitivo, sino también que este centro es la raíz de ambas ramas" (Heidegger, 1993, p. 167). Muy heterodoxamente, Heidegger interpretará la $\mathrm{CrP}$ como ajena a la teoría del conocimiento, en un compromiso de determinación del problema metafísico que no sería otro que la fundamentación de la subjetividad del sujeto basada en la finitud de su inexorable temporalidad (Garrido, 2019). De este modo, nuestra lectura de la imaginación tendrá probablemente muy poco de kantiana, sobre todo porque el meollo del asunto es una presentación asaz confusa, que el mismo Kant hace de esta facultad. Una conjetura plausible, y que parece calzar con cierta comodidad con la tesis de Heidegger acerca del retroceso de Kant, es la de considerar lo que el filósofo prusiano menciona en la deducción de los conceptos puros del entendimiento: "La síntesis reproductiva de la imaginación forma parte de los actos trascendentales del psiquismo y por ello llamaremos a esta facultad la facultad trascendental de la imaginación" (Kant, 1998, A 102). Esta aparente contradicción en los términos con que hasta ahora 
el filósofo regiomontano había venido planteando la cuestión de la imaginación, esto es, que la síntesis reproductiva era propia de la imaginación empírica, mientras que la síntesis productiva lo era de la imaginación trascendental, parece resolverla Heidegger (1993) al considerar "que la imaginación trascendental, como intuición pura finita, no solamente puede, sino que debe ser sensible, en tanto determinación fundamental de la trascendencia finita" (p. 129).

El trabajo se organiza como sigue: primero, se aborda el problema que representa la síntesis trascendental para la unidad del conocimiento kantiano en confrontación con la recepción heideggeriana de 1929; en segundo lugar, se desarrolla el asunto de la finitud de la trascendencia como fundamento de la posibilidad interna de la metafísica con base en el tiempo; enseguida, se discute la presunta violencia hermenéutica que subyacería en la crítica de Heidegger a Kant, con un guiño a los comentarios de Žižek y Castoriadis. Por último, se plantea la pregunta acerca de si esta incisión en la filosofía kantiana del conocimiento podría ser vista o no como apropiación de Kant por parte de Heidegger.

\section{El problema de la síntesis}

Partamos de la consideración de que en Kant la ontología "se estudia en la Analítica Trascendental de la $\mathrm{KrV}$, tanto de los Conceptos como de los Principios. Por eso proporciona conocimiento sintético a priori de Objetos sensibles en general al mismo tiempo que es una mera analítica del Entendimiento" (Villacañas, 1987). Esto es muy relevante puesto que, si en gran medida la $\mathrm{Cr} P$ constituye el rasero crítico de Kant para establecer los límites y alcances de toda metafísica, no debe desatenderse que precisamente esta ontología que subyace a la primera crítica constituye la filosofía trascendental cuando se la considera desde un sesgo metodológico (Villacañas, 1987). Tampoco olvidemos que una de las conclusiones cardinales de Kant y el problema de la metafísica es que "la esencia de la trascendencia se basa en la imaginación pura, es decir, en la temporalidad en un sentido más originario" (Heidegger, 1993, p. 204). Entonces: trascendencia e imaginación forman en Kant, a partir de la profundización del problema de la finitud, el meollo de la ontología fundamental (Heidegger, 1993). En la primera edición se define así a la imaginación trascendental:

Facultad del alma humana [...] que sirve de base a todo conocimiento a priori. Por medio de ella combinamos lo diverso de la intuición, por una parte, y, por otra, lo enlazamos con la condición de unidad necesaria de la apercepción pura. Ambos extremos, es decir, sensibilidad y entendimiento, tienen forzosamente que interrelacionarse a través de esta función trascendental de la imaginación, ya que, en caso contrario, dichos extremos suministrarían fenómenos, pero no objetos de conocimiento empírico, ni, por tanto, experiencia alguna. (Kant, 1998, A 124)

Esta "interrelación" o "enlace", como se sabe, es la triple síntesis de la imaginación, que determina finalmente la aprehensión, la asociación y el reconocimiento de los fenómenos en cuanto objetos de la experiencia sensible. Veamos brevemente en qué consiste cada una de estas síntesis particulares, que se describen en la deducción de los conceptos puros del entendimiento. Señala Kant (1998) sobre la síntesis pura de aprehensión: "Toda intuición contiene en sí una variedad que, de no distinguir el psiquismo el tiempo en la sucesión de impresiones, no sería representada como tal" (A 99). Tal como indica el filósofo prusiano, esta síntesis tiene que verificarse a priori, vale decir, con respecto a representaciones no empíricas, pues sin esta síntesis, "no podríamos tener representaciones a priori ni del espacio ni del tiempo, ya que estas últimas solo pueden producirse gracias a la síntesis de lo vario ofrecido por la sensibilidad en su originaria receptividad" (A 99). Así, la síntesis pura de aprehensión constituye el fundamento trascendental de la posibilidad de todo conocimiento, no solo del empírico, sino también del puro a priori. La segunda síntesis, la de reproducción en la imaginación, es la "síntesis trascendental pura de la imaginación, una síntesis que, a su vez, servirá de base a la posibilidad de toda experiencia, ya que esta, en cuanto tal experiencia, presupone 
necesariamente la reproductibilidad de los fenómenos" (Kant, 1998, A 101). A decir de Villacañas (1987), es la operación "que tiene por finalidad jugar con las percepciones, relacionarlas entre sí de una manera peculiar" (p. 98). La última síntesis, de reconocimiento en el concepto, es presentada por Kant (1998), no digamos de forma oscura, pero sí algo enmarañada:

Ahora bien, no es posible tal unidad [de la síntesis en lo diverso de la intuición] si la intuición no ha podido ser originada, según una regla, por una función tal de síntesis, que, por una parte, haga posible un concepto en el que la diversidad se unifique $\mathrm{y}$, por otra, haga necesaria a priori la reproducción de esa misma diversidad. (A 105)

Dicha síntesis implica que la conciencia del sujeto trascendental debe ser capaz de darse a sí misma la unidad sintética de la reproducción de la diversidad de los fenómenos dados. Tal conciencia es la apercepción trascendental, "esa conciencia pura, originaria e inmutable" (Kant, 1998, A 107), fundamento sin el cual "sería imposible pensar un objeto de nuestras intuiciones, ya que este objeto no es más que el algo cuyo concepto expresa dicha necesidad de síntesis" (A 106). Es decir: para que tenga sentido la reproducción, tenemos que reidentificar lo que hemos percibido en lo que recordamos, y tal reidentificación exige la aplicación de un concepto (Stepanenko, 2005). Nótese que las palabras de Kant (1998) en la primera edición son suficientemente claras sobre el papel decisivo de la imaginación en la labor del conocimiento: "La unidad trascendental de la síntesis de la imaginación constituye la forma pura de todo conocimiento posible y, consiguientemente, la forma mediante la cual tiene forzosamente que representarse a priori todo objeto de experiencia" (A 118).

Pues bien, para Heidegger la síntesis trascendental queda convertida en cuanto síntesis a priori en síntesis ontológica, en el entendido de que el problema del conocimiento para Kant remite necesariamente a la cuestión del ente, esto es, al fenómeno y a la posibilidad de conocerlo. A ojos del filósofo de Friburgo, la $\mathrm{CrP}$ interroga por la posibilidad esencial de la síntesis ontológica, y, en tal sentido, la pregunta acerca de la síntesis pura determinará al mismo tiempo el proyecto de la posibilidad interna de la ontología (Heidegger, 1993). La ontología, piensa el alemán, constituye la esencia de la razón pura finita. Sin embargo, la pregunta decisiva que Heidegger se hace en esta fundamentación trascendental del conocimiento ontológico es acerca de la posibilidad interna de la unidad esencial de la síntesis ontológica. O sea, acerca de la posibilidad de que la síntesis pura se haga patente "como lo que junta y sostiene la totalidad unida de la estructura esencial interna de la trascendencia" (Heidegger, 1993, p. 67). Esta interrogación, como veremos luego, le permitirá a Heidegger observar con encomiable perspicacia que la triple síntesis de la imaginación trascendental, en su faena de aprehensión, de reproducción y de reconocimiento, conlleva previamente la fundamentación de un tiempo originario, en cuanto esta posibilidad a priori de la representación está determinada simultáneamente por la reunión de pasado-presente-futuro inmediatos (Vargas, 2018). La idea de Kant de que el tiempo es permanente y no transitorio hace posible que Heidegger (1993) afirme que como sucesión pura de los ahoras el tiempo es siempre ahora:

El tiempo no es algo permanente entre otros, sino que es el que da, precisamente sobre la base del mencionado carácter esencial de ser ahora en cada ahora, el aspecto puro de algo así como un permanecer en cuanto tal. (p. 97)

De modo que la síntesis pura de la imaginación permite la unidad de la esencia plena del conocimiento puro, unidad que está formada por lo múltiple de la intuición pura, por la síntesis de eso múltiple en la imaginación y por la determinación de los conceptos que dan unidad a esa síntesis pura. Heidegger enfatizará que esta unidad sinóptica constituye verdaderamente el fundamento del conocimiento ontológico, y llamará síntesis veritativa pura a aquella síntesis que concierne a la unidad de la intuición y el pensamiento. De esta laya, la triple síntesis supondrá una síntesis de lo recorrido, al modo de un representar intuitivo; una síntesis 
de lo recogido, que corresponderá al representar imaginativo propiamente tal; y una síntesis de lo reunido, que estará referida al representar pensante. El esquema de Heidegger da tanta preponderancia a la actividad sintética de la imaginación, que bien podría hacerse un parangón entre las ideas de "raíz" y "síntesis", ambas centradas en el rendimiento ontológico de la imaginación. Al menos eso parece pensar Holguín de Torres (1983):

El proyecto mismo de buscar un fundamento de las facultades en otra facultad y de calificar dicho intento de "síntesis original" implica por sí mismo una interpretación unilateral tanto de la filosofía trascendental como de la noción de síntesis. Dicha noción puede ser considerada tan importante en la elaboración de la filosofía crítica que si algo ha de considerarse como la esencia del conocimiento sería - no la intuición- sino la actividad sintética misma. (p. 87)

En su influyente Desconocida raíz común (1987), Felipe Martínez-Marzoa no solo coincide con la interpretación heideggeriana sobre el retroceso de Kant ante la imaginación trascendental, sino que, yendo más lejos, subraya que Kant habría decidido no tematizarla, justamente llamándola "desconocida raíz común" en su afán de considerarla como una especie de "Big Bang" ontológico de donde manarían como "dos troncos" la sensibilidad y el entendimiento. Observa el filósofo español:

Y esto [afirmar que ni la sensibilidad es raíz ni tronco del entendimiento ni viceversa] es lo que hace Kant cada una de las veces en que expone que la sensibilidad es esencialmente pluralidad, que la pluralidad solo tiene lugar en una síntesis y que la síntesis [...] comporta que el modo de enlace, el procedimiento de construcción se independice qua regla; o lo que es lo mismo, dicho en orden inverso e igualmente válido, a saber: que la unidad del objeto (correlato de la unidad de la apercepción pura), en la cual tiene su consistencia el concepto, solo puede ser unidad como unidad de algo y, por lo tanto, solo en cuanto fijación de la regla inherente a una síntesis. (Martínez-Marzoa, 1987, pp. 33-34)
Es decir: la síntesis sería la moneda cuya cara y sello vienen a ser indistintamente el concepto y la sensación, en el fin primordial de constituir trascendentalmente el entendimiento como una facultad distinta (Martínez-Marzoa, 1987). La indicación proyecta a la imaginación trascendental bastante más allá de la deducción de los conceptos puros del entendimiento. Dicha "desconocida raíz común" -y este es un comentario de suyo relevante para toda la arquitectónica del sistema kantiano- va a tener un rol fundamental en la génesis de la tercera crítica, en el sentido de que jugaría no solo el papel de raíz común entre la sensibilidad y el entendimiento, "sino a la vez como raíz común de la Razón cognoscitiva y la Razón práctica" (Martínez-Marzoa, 1987, p. 35). Ahora, siguiendo la argumentación heideggeriana, imaginación trascendental y tiempo aparecen concomitantemente asociados al problema de la trascendencia del conocimiento ontológico. De esta forma la síntesis reproductiva de la imaginación puede contarse entre los actos trascendentales de la mente, puesto que la reproducción de las intuiciones pasadas no tiene raíz en el reino empírico.

\section{Imaginación, tiempo, existencia}

Decisivamente, la recepción de Heidegger de la CrP está determinada por la temporalidad del Dasein. Baste tener en cuenta la época en la que el filósofo publica su texto sobre Kant, solo un par de años después de la publicación de Ser y tiempo. Sin embargo, debemos al propio Kant este "flanco de la temporalidad" en la $\mathrm{CrP}$ y que Heidegger elige como centro de su crítica ontológica. En efecto, afirma Kant (1998): "Por consiguiente, el principio supremo de todos los juicios sintéticos consiste en que todo objeto se halla sometido a las condiciones necesarias de la unidad que sintetiza en una experiencia posible lo diverso de la intuición" (A 158). La pregunta natural, entonces, es en qué consiste este "sometimiento" de todo objeto de la experiencia posible, y cuáles son estas "condiciones necesarias de la unidad de síntesis". Respuesta: se trataría de que los objetos del mundo susceptibles de ser conocidos, solo pueden serlo en cuanto el sujeto a partir de la 
síntesis pura de la imaginación precisamente los "somete" a una determinación trascendental del tiempo. Heidegger (1993):

Este principio fundamental no es, de ningún modo, un principio obtenido a posteriori al que hay que tener por valedero, si ha de valer la experiencia; es, por el contrario, la expresión del conocimiento fenomenológico originario de la estructura interna y unida de la trascendencia. (p. 106)

Refiriéndose a la detención de la sucesión indefinida del tiempo en la continuidad de las intuiciones de la síntesis ontológica, Heidegger suscribirá que el tiempo no es solo la única posibilidad de transformar esta multiplicidad de datos en una imagen pura, sino también su única posibilidad de aspecto puro. Conviene aquí reiterar la principal idea de Heidegger sobre el papel de la síntesis ontológica, esto es, que la imaginación pura, mediante su acción formadora en virtud de un tiempo originario, determina la posibilidad de que el sujeto pueda proyectarse respecto de los objetos del mundo en un espectro circunscrito y finito. De este modo trascendencia y finitud se superponen, en un instante de conciencia del sujeto que perfectamente podemos llamar, con Heidegger (1993), existencia:

Esto implica que el conocimiento ontológico -entendido siempre como conocimiento preontológico-es la condición de posibilidad para que un ser finito pueda ob-jetivarse en general a algo así como el ente mismo. El ser finito ha menester de esta facultad fundamental de orientarse hacia..., dejando que algo se le ob-jete. En esta orientación originaria el ser finito se pro-pone un margen libre, dentro del cual es posible que algo le "corresponda". (p. 67)

O como lo indica más adelante: "El tiempo no solo da a la trascendencia una consistencia previa y unida, sino que le ofrece algo así como una pausa, conforme a su carácter de lo que se da puramente como tal" (Heidegger, 1993, p. 98). Esta pausa, por cierto, es el "ahora" en que el sujeto reconoce al objeto como tal, es decir, asociado a un concepto determinado. No se trata, pues, de un horizonte temporal indeterminado en el que la operación cognoscitiva tendría lugar solo de manera quiditativa. Al contrario, cree Heidegger, es la finitud de la trascendencia la que sirve de base a la posibilidad interna de la metafísica. Resumiendo: para Heidegger la posibilidad de la experiencia equivale a la trascendencia. Esto significa que la trascendencia hace accesible el ente en sí mismo a un ser finito. O sea, el objeto de la estructura cognoscitiva kantiana se presenta como un objeto trascendental. Esta presentación se expresa como un oponerse del ente en la trascendencia, de tal forma que puede ser captado por ella como su horizonte puro. Así, la tarea de formación de la trascendencia gravitará en la fuerza formadora de la imaginación, de donde Heidegger subrayará que la imaginación trascendental es el fundamento de la posibilidad interna del conocimiento ontológico. En otras palabras, la imaginación solo forma el aspecto de un objeto posible (es, pues, la raíz de la trascendencia), el que tal vez pueda producirse (llevarse a la presencia) bajo determinadas condiciones. Esta idea de Heidegger es sumamente importante, pues deja en claro que su lectura de la problemática ontológica de la $\mathrm{CrP}$ gira en torno al esclarecimiento de la esencia finita de la razón, finitud que precisamente logra inferirse de su sujeción a la intuición (Martínez-Matías, 2018).

El esclarecimiento ontológico deducido por Heidegger (1993) a partir de la analítica trascendental reza así: "La revelación de la constitución del ser del ser-ahí es ontología [...] se llama ontología fundamental en tanto establece el fundamento de la posibilidad de la metafísica, es decir, en tanto considera la finitud del ser-ahí como su fundamento" (p. 195). Dicha finitud, en tanto proyección del ser del ente, le permitirá a Heidegger pensar la comprensión de este proyectar como existencia. Siendo evidentes las diferencias "doctrinarias" entre uno y otro proyecto -el de Kant y el de Heidegger-, y tal como sostiene Martínez-Matías (2018), no deja de ser impensada la afinidad que el filósofo de la Selva Negra halla entre el conocimiento trascendental y el resultado provisional de la indagación ontológica desarrollada en Ser y tiempo. No cometeremos el error de discutir acá, en unos pocos párrafos, las 
circunstancias en que la filosofía kantiana podría ser entendida como fenomenología, o cuáles pudieran ser sus conexiones con fenomenologías más modernas. Mas, convengamos que la referencia en la analítica trascendental a la existencia, o, para decirlo con los términos de Heidegger, a la posibilidad de la trascendencia como esencia del sí-mismo finito, parece confirmar que lo que esencialmente revela es el horizonte de la objetividad como manifestación fenoménica.

La hermenéutica heideggeriana de la $\mathrm{CrP}$ es de una fuerza tal, en especial respecto de la deducción trascendental, que no puede menos que socavar la monumentalidad de la arquitectónica de una primera crítica, que el kantismo había sabido construir sobre todo a partir del axioma methodus antevertit omnem scientiam [el método es lo primordial en toda ciencia], consignado por Kant en De mundi sensibilis atque intelligibilis forma et principiis (1770). Lo cardinal en el primer Heidegger sigue siendo la pregunta por la trascendencia, cuya posible respuesta buscará afanosamente en la crítica de Kant. Ahora, la preocupación de Heidegger es ontológica-trascendental, de ahí que su formulación metodológica se dé bajo la denominación diferencia ontológica (Sola, 2000). Trascendental y trascendencia, entonces, no son ni yuxtaposiciones semánticas ni términos, como quien dice, canjeables en la nomenclatura heideggeriana. La trascendencia precisamente le da al hombre el sentido de persona-humana (Sola, 2000), de donde trascendental y trascendencia equivalen, yendo a la esencia de la metafísica, al binomio ontológico/óntico. Ahora bien, la imaginación, dirá Heidegger (1993), al donar el tiempo originario como horizonte de la trascendencia constituye al mismo tiempo al sí-mismo como temporal:

El tiempo, de acuerdo con su esencia, es afección pura de sí mismo. Es más, es precisamente lo que forma el tender-desde-sí-mismo-hacia, de tal suerte que el "hacia" así formado mira atrás y penetra con la vista la susodicha tendencia hacia... (p. 161)

Al proponerse a sí mismo como receptividad formadora, el tiempo forma la estructura esencial de la subjetividad. Es decir, Heidegger desarrolla una explicación ontológica-existencial de la temporalidad y luego muestra cómo se deriva de ella el concepto tradicional de tiempo (Massey, 2015, p. 88).

\section{¿Violencia hermenéutica?}

La interpretación que hace Heidegger de Kant, pero sobre todo la "intensidad" de su crítica, tiene tantos adherentes como detractores. El lugar común parece situarse en la vehemencia hermenéutica con que Heidegger fustiga en el filósofo de ojos azules su retroceso ante el fundamento que ha descubierto al revelar la subjetividad del sujeto. Yendo un poco más lejos, la crítica de Slavoj Žižek no solo se dirige al proyecto político heideggeriano y su compromiso nazi (Fayé, 2018), sino en particular a lo que él considera una inadmisible negligencia de Heidegger en sus observaciones sobre el Kant de la $C r P$. Desde esta trinchera, el filósofo esloveno enfatizará un asunto que hasta ahora no había sido recogido explícitamente ni por la crítica kantiana ni la heideggeriana. A diferencia de Heidegger, Žižek (2001) plantea que "el misterio de la imaginación trascendental en cuanto espontaneidad reside en el hecho de que es imposible situarla adecuadamente con respecto a la pareja de lo fenoménico y lo noumenal" (p. 35). Este comentario se dirige no solo al flanco epistémico-ontológico de Kant, a través de la omisión de Heidegger, sino específicamente, creo yo, al Kant político, a aquel que se ha vinculado en distintos lugares y con distintos tonos a la denominada cuarta crítica (Rodríguez-Aramayo, 1992; Freudiger, 1996; Grondin, 2000; Brandt, 2006).

Esta "cuenta pendiente" que Žižek deriva del análisis del problema de la imaginación en Kant, se resume en una analogía que hace el filósofo neo-marxista entre la espontaneidad trascendental y la imaginación trascendental: por un lado, estamos como fenómenos atrapados en una red de conexiones causales, y por otro, y al mismo tiempo, al ser moralmente libres quedamos determinados en nuestra condición noumenal. A juicio de Žižek, Kant dirime las antinomias dinámicas de la razón mediante la asignación de la posibilidad de veracidad 
para ambas proposiciones. Esto es estrepitoso para Žižek porque, si así fuera, la libertad trascendental quedaría virtualmente en una zona intermedia entre lo fenoménico y lo noumenal, desvaneciéndose si el sujeto tuviera un acceso directo al orden noumenal:

Lo que desdibuja este cuadro claro es la comprensión que el propio Kant tiene de las consecuencias catastróficas de nuestro acceso directo a la esfera noumenal: si este acceso existiera, los hombres perderían su libertad moral y su espontaneidad trascendental; se convertirían en títeres inertes.

(Žižek, 2001, p. 35)

Esta inconsistencia en la determinación del estatus ontológico exacto de la libertad, cree Žižek (2001), coincidirá con el misterio de la imaginación trascendental. Sin embargo, el filósofo-psicoanalista va aún más lejos, posiblemente todo lo lejos que Heidegger no se atrevió a ir. En su interpretación, Kant zozobra en la $\mathrm{CrP}$ entre un camino propiamente ontológico y uno, por así decir, especialmente práctico, en el sentido de que la constitución trascendental de la realidad a la que se enfrenta abre un abismo infranqueable si se echa mano a los atributos epistémicos de su misma crítica. Este es el momento preciso en el que Žižek arremete, por sobre la capitulación de Heidegger, con su idea de la "tercera vía”. Para el filósofo esloveno, la idea kantiana de constitución trascendental de la realidad precipita un tercer dominio específico, que no es fenoménico ni noumenal, sino preontológico en sentido estricto. Por la relevancia de la observación, cito en detalle:

O, para decirlo de otro modo, la pulsión de muerte no es lo Real noumenal presubjetivo en sí mismo, sino el momento imposible del "nacimiento de la subjetividad", del gesto negativo de contracción/ repliegue que reemplaza la realidad por membra disjecta, por una serie de órganos como sustitutos de la libido "inmortal". Lo Real monstruoso que ocultan las ideas racionales no es lo noumenal, sino ese espacio primordial de la imaginación presintética "salvaje", el dominio imposible de la espontaneidad, la libertad trascendental en su aspecto más puro, anterior a su subordinación a cualquier ley autoimpuesta, el dominio vislumbrado por momentos en diversos puntos extremos del arte posrenacentista, desde Jerónimo del Bosco hasta los surrealistas. Este dominio es imaginario, pero no todavía como identificación especular del sujeto con una imagen fija: es anterior a la identificación imaginaria que da forma al yo. (Žižek, 2001, p. 64)

La epistemología kantiana expresa, para Žižek, "una falla en el sujeto, una ontología incompleta que luego será 'reparada' en sus estudios sobre ética, en especial cuando asume el imperativo categórico como lo incondicionado asumiendo las características propias de las ideas de la razón" (Sicerone, 2017). Vale decir: Žižek piensa que Kant (a quien no por nada llama el filósofo de la universalidad abstracta) retrocedió ante su propio descubrimiento de una imaginación como fondo de la subjetividad más primitiva del hombre, del núcleo fantasmático que pone en "riesgo doctrinario" el estatus de la libertad trascendental. No es que Kant haya vislumbrado el abismo fundamental entre sensibilidad y entendimiento, el fondo "salvaje" de la subjetividad, sino que realmente "vivió" el acceso al ámbito noumenal. Žižek (2001): "No sorprende que esta visión de un hombre que se convierte en títere inanimado debido a su percepción directa de lo monstruoso del 'ser en sî' divino haya provocado semejante incomodidad entre los comentadores de Kant" (p. 72). A partir de aquí la argumentación del filósofo de Liubliana se oscurece, y, se diría, penetra sin retorno en el ámbito cosmológico, problema que, faltaba más decirlo, excede las posibilidades de este trabajo. Baste como corolario a esta breve exégesis sobre la crítica de Žižek (2001) al Kant de Heidegger, un comentario que avisa la dirección ulterior de su análisis filosófico-patológico sobre el pensador prusiano: "En síntesis, Heidegger no puede abordar la dimensión excesiva de la subjetividad, su locura intrínseca, precisamente debido a que limita su análisis del esquematismo a la analítica trascendental" (p. 74).

Similar crítica (política, ontológica, histórica) hace a Kant el filósofo grecofrancés Cornelius Castoriadis. En este caso, no se trata solo de reparar en el retroceso kantiano ante la imaginación, sino derechamente de "dar vuelta las cosas" con relación a la sensibilidad, de ver transformada su limitada 
labor gnoseológica en una preeminente tarea formadora de mundo. Aunque, a decir verdad, Castoriadis va más lejos de una mera ontología fundamental y se lanza a las aguas de una filosofía de la historia, cuyo concepto clave parece ser el de creación ontológica. Después de coincidir respecto del retroceso kantiano, critica a Heidegger su no menos decisivo olvido de este descubrimiento: "Y posteriormente, después del libro de 1928, repitiendo por tercera vez la misma historia, Heidegger no vuelve a decir ni una sola palabra sobre la imaginación" (Castoriadis, 1999, p. 93). Al parecer, el ajuste de cuentas es con Heidegger, y no con Kant. En tal sentido, la deuda por pagar del filósofo de la Selva Negra tiene que ver, por una parte, con su despreocupación acerca del papel ontológico-político de la imaginación: “Por qué la filosofía jamás supo reconocer esta necesidad [la fuerza de creación de lo imaginario social instituyente], y por qué sigue retrocediendo horrorizada e irritada ante esta idea?" (Castoriadis, 1999, p. 94), argumento referido a una defensa de la imaginación como facultad constituyente del colectivo humano, $y$ al mismo tiempo con una crítica a lo que Castoriadis llama "filosofía heredada"; pero, por otra, con una crítica ontológica -y quizás también cosmológicacentrada en la noción de límite formal.

Al revés de Heidegger, Castoriadis postulará como tarea indispensable de la filosofía, especialmente en relación con el pensamiento antiguo, la restitución de la matriz de sentido en la que dicho pensamiento fue producido y comprendido (Aldegani, 2016). De suerte que para Castoriadis la creación es ante todo creación de la imaginación, pero una tal que está definida por una delimitación formal, que estructura y determina formalmente a los entes (Aldegani, 2016). El tiempo, así, llega a definirse mitológicamente, como si el mythos pudiera cautelar con mayor fiabilidad la comprensión del tiempo en tanto emergencia de la alteridad:

Cronos, el tiempo mismo es quien derroca el poder consolidado de Urano, pero luego este es derrocado por Zeus, que es un dios esencialmente político frente a los anteriores. Este, sin embargo, será finalmente derrocado. Para quien se halla familiarizado con la filosofía de Castoriadis se comprende rápidamente la relevancia de estos acontecimientos, pues una estructura inicial es derrocada por la figura del tiempo, y cabe recordar que el tiempo es definido por Castoriadis principalmente como emergencia de alteridad, irrupción de lo nuevo sobre lo dado. (Aldegani, 2016, p. 246)

La idea de Castoriadis de una imaginación dotada de una especie de fuerza maquinal creadora y recreadora de las entidades del mundo, a la larga, no está tan lejos del neo-marxismo de Žižek. Ambos autores, a diferencia de Kant, reservan a la imaginación un papel primordial desde un punto de vista primitivamente ontológico. Es más, la imaginación cumple en Castoriadis, al igual que en el Kant leído por Heidegger, una suerte de rol fundante entre la dimensión gnoseológica y la política. Cada una de estas dimensiones son comprendidas por Castoriadis como niveles de ser, "como estratificaciones ontológicas no determinadas y unidas por ser portadoras de un sentido -inestable, disfuncional- que no derivan de un ámbito ontológico predeterminado, sino que deben entenderse como terreno de creación" (Pedrol, 2003, p. 168). Como bien advierte Papadimitropoulos (2020):

La libertad radical de lo imaginario es sinónimo de novedad ontológica derivado de la lógica-ontología de Magmas de Castoriadis y expandiéndose en consecuencia en su pensamiento epistemológico y político. En la ontología de Castoriadis, Ser es Caos o Abismo, cuyos principales atributos son la indeterminación y la creación. (p. 42)

Ahora bien, ¿por qué Castoriadis y Žižek?, o lo que es lo mismo, ¿cómo determinan Castoriadis y Žižek nuestra recepción del Heidegger lector de Kant? La llave para dar con una respuesta satisfactoria está, todo indica, en la propia maniobra heideggeriana de "beber" de la síntesis ontológica kantiana para determinar la posibilidad de la analítica existenciaria del Dasein. En otras palabras, para "armar" ontológicamente la fenomenología del Dasein. Justamente, la famosa intuición de Heidegger acerca del retroceso de Kant ante el papel de la imaginación trascendental parece servir 
también al filósofo de Friburgo para corroborar la idea de una trascendencia apegada a la noción de mundo, zafando de posiciones más irracionalistas, por ejemplo, como las de Žižek y Castoriadis. Para decirlo ficticiamente, es Heidegger quien retrocede ante ambas filosofías de la subjetividad. Más explícitamente: Heidegger retrocede ante la propia imaginación primitiva y monstruosa de Žižek, que parece desnudar in toto la ontología trascendental de Kant, y desclasificar el que la analítica existenciaria de Ser y tiempo se hubiera apropiado de la misma legalidad de la razón. Pero Heidegger huye también de Castoriadis, de la revelación de una imaginación ya no solo entendida como aquella "desconocida raíz común", sino esencialmente pensada como una máquina creadora de mundo, una especie de máquina infernal que se hubiera tragado simultáneamente al mythos y al tiempo.

\section{Incisión, ¿apropiación?}

La incisión teórica que Heidegger provoca en la tesitura trascendental de la $\mathrm{CrP}$ parece ser de la "mayor profundidad". Apunta Heidegger (1993): "El tiempo, como intuición pura, es a la vez la intuición formadora y lo intuido por ella [...]. Es la imaginación trascendental quien da nacimiento al tiempo como serie de ahoras y quien, por dar nacimiento a este, resulta ser el tiempo originario" (pp. 150-151). De manera que el fundamento de la posibilidad de intuir el mundo, la sensibilidad pura, remite originariamente al tiempo. El tiempo y el "yo pienso" son, pues, lo mismo.

Es indudable que la crítica de Heidegger a Kant constituyó una maniobra teórica para la fundamentación de Ser y tiempo. Heidegger señala en el prefacio a la edición en alemán: "El refugio así determinado condujo a la 'Crítica de la razón pura' en la perspectiva de la pregunta interpretada por 'Ser y Tiempo', pero de hecho la pregunta le era extraña a Kant, aunque la cuestión estaba condicionada subrepticiamente" (Heidegger, 1991, XIV). De esta crítica, lo decisivo resultó ser que la fundamentación kantiana de la metafísica se transformó "en la aclaración de la posibilidad interna de la comprensión del ser" (Heidegger, 1993, p. 190). Esto quiere decir que el problema de la fundamentación de la metafísica se enraíza en la pregunta por el fundamento íntimo del Dasein, en la pregunta por la comprensión del ser como finitud esencialmente existente (Heidegger, 1993). La concomitancia ontológica entre el resultado de la crítica a Kant y las bases de Ser y tiempo equivaldrá, dice Pardon (2015), a la estructura del cuidado:

En Ser y tiempo, Heidegger establece que una de las estructuras ontológicas del Dasein es la cura o cuidado, es decir, el estar arrojado en el mundo junto a los entes que comparecen. En ello consiste la trascendencia, la esencia del existente humano. El Dasein es un proyecto, caído en el mundo dentro del cual le hacen frente los entes. En tanto existencia finita, la trascendencia del Dasein no consiste en un ir más allá de esa finitud. La trascendencia es el estar arrojado en el mundo, en el cual, esa finitud se realiza. (p. 5)

La idea de que Heidegger se haya apropiado de Kant no es nueva. De hecho, la repetición de la cuestión del ser ocurre en el horizonte trascendental de tiempo, lo que constituye un enlace de gran valor teórico cuando se pretende conectar la crítica kantiana de la metafísica con la destrucción de Heidegger de la metafísica tradicional (Barreto, 2012). Así, la posibilidad de que la metafísica de Kant haya actuado como puente para la analítica de Ser y tiempo requirió, antes que todo, que Heidegger despejara la cuestión de la síntesis trascendental, es decir, que el significado del ser finalmente no requiriera de la analítica trascendental, sino de un análisis existencial, que es parte precisamente de la perspectiva de la trascendentalidad del Dasein (Barreto, 2012).

Lo evidente es que la fisura en el sistema trascendental -advertida o no por Kant al momento de enfrentarse a la productividad ontológica de la imaginación- constituyó la caída del velo de Maya para la consideración de Heidegger (1997) de que "el sentido ontológico del cuidado es la temporeidad" (p. 380). De esta manera, el papel insospechado de la imaginación como fundamento de la metafísica de 
Kant (el puente entre ontología crítica y experiencia hermenéutica), pavimenta el camino para la borradura del sujeto metafísico. Poole (2013):

Pero antes de realizar tal salto, primero veremos cómo Heidegger se prepara para ello, de hecho, descubre un peldaño dentro del propio aparato trascendental de Kant, que demuestra cómo, sin que Kant lo supiera, abrió el camino para un debilitamiento mucho más radical de la seguridad del sujeto soberano y su metafísica. (pp. 120-121)

¿Es la imaginación trascendental el único peldaño que puede remitir a la idea de una apropiación de Kant por parte de Heidegger?

No estamos seguros de una respuesta que no deje dudas, pero si miramos solamente al mundo de la ética, dejando fuera, por ejemplo, el ámbito de la estética, donde la construcción de una ontología de la plasticidad será primordial en el Heidegger tardío, caeremos en cuenta que hay otra estructura cuya función presenta similitudes palmarias entre una y otra filosofía. Tal estructura es la conciencia, que actúa en el hombre como una subrepticia interpelación. Si la conciencia kantiana actúa como una exhortación acusadora de la razón pura práctica del sujeto finito, en Heidegger -análogamente- es en la llamada al modo de ser propio del Dasein donde este se apropia de sí mismo, como proyecto arrojado, frente al estado de impropiedad en el que habitualmente se halla (Gómez-Sánchez, 2011). Leemos en Ser y tiempo: "El Dasein mismo llama en cuanto conciencia desde el fondo de este estar [...]. La llamada templada por la angustia le hace posible por primera vez al Dasein proyectarse a sí mismo en su más propio poder-ser" (Heidegger, 1997, pp. 296-297). Y ante el probable argumento que inclinaría el peso del deber moral hacia la esfera trascendental: "a la luz del rodeo por el sentimiento de respeto, se estaría en condiciones de afirmar que la conciencia kantiana, en tanto que disposición moral, también hace patente la condición del yo como pro-yecto (trascendencia) finito" (GómezSánchez, 2011, p. 152).

Una salida más mesurada -algo así como una "tercera vía" - parece ser aquella que indica que el interés puntilloso de Heidegger por Kant tiene que ver fundamentalmente con la riqueza que el pensador de Friburgo aquilató en la filosofía trascendental, en la que halló un ángulo completamente nuevo desde el cual formular la cuestión del ser (Schalow, 1994). Argumenta el filósofo estadounidense: "Sin duda, podríamos continuar afirmando la centralidad de esta doctrina debido a su enfoque temporal $y$, por lo tanto, asumir la plausibilidad de la decisión de Heidegger de llevar a Kant a la vanguardia de su propia investigación ontológica" (Schalow, 1994, p. 104). Después de todo las concomitancias entre Heidegger y Kant, a propósito del problema de la finitud de la existencia, no representan sino el reconocimiento del carácter fenomenológico de la investigación ontológica misma, carácter que ya está implicado en la propia distinción de lo ontológico frente a lo óntico (Martínez-Marzoa, 1999).

La pregunta en torno a una posible recepción heideggeriana de Kant como apropiación o como aclaración de la posibilidad interna de la comprensión del ser, únicamente puede contestarse a partir de las implicancias ulteriores de la filosofía de Heidegger. Tales implicancias, como se ha visto, no renuncian a la pregunta por lo trascendental, que en Heidegger pasa a convertirse en la pregunta por el ser. Lo que ocurre es que la respuesta que da el filósofo de Messkirch, precisamente a partir de su exégesis de lo trascendental kantiano, inopinadamente toma la forma técnica de la diferencia ontológica, de la diferencia entre ente y ser, siendo el Dasein el ente comprensor del ser, el que debe responder a esta problemática (Sola, 2002).

Pero ¿tiene el propio proyecto filosófico de Heidegger algún tipo de "deuda" con la primera crítica, en especial a partir de la noción de lo trascendental, que se ha revelado como una suerte de "caldo primordial" ontológico, en razón, como se ha pergeñado, de la fuerza formadora de la imaginación trascendental? Nuestra interpretación es que sí, en el sentido de que, si es precisamente la imaginación pura, como quien dijera, la llave de la constitución fenoménica del mundo, o dicho con más propiedad aún, del conocimiento ontológico 
(Heidegger, 1993), todo indica que la idea de trascendencia, uno de los problemas cardinales del primer Heidegger, le debe a Kant algo más que una mera aclaración de índole lógica o epistémica. La noción de trascendencia en Heidegger -consolidada ontológicamente luego del estudio sobre Kant de 1929- se liga transitivamente con la concepción de ser, justamente a partir de la metodología desarrollada en Ser y tiempo. Trascendencia, afirma Heidegger (2007), es "la constitución originaria de la subjetividad de un sujeto" (p. 195). Es decir, trascender no es meramente vivir el Dasein el mundo en el que se halle arrojado. Se trata de "hacer" el mundo, de que el Dasein lo construya "por mor de" la estructura voluntad/libertad. Empero, antes de esta posibilidad, por así decir, fenoménica, debe darse que el mundo de manera previa esté extáticamente abierto: "Por estar fundado en la unidad horizontal de la temporeidad extática, el mundo es trascendente" (Heidegger, 1997, p. 381). Trascendencia, entonces, mienta un lugar privilegiado del Dasein como un ente del mundo: es su determinación existencial fundamental. Sostiene Heidegger (2007) con extrema elocuencia: "Si la trascendencia en el sentido del ser-en-el-mundo es la constitución metafísica fundamental del Dasein, entonces una metafísica del Dasein, con suficiente intención ontológica fundamental, debe señalar esta constitución fundamental desde el principio" (p. 196).

Tomando en cuenta el excelente estudio de Sola (2000), bien podemos suponer que la trascendencia para Heidegger equivale en realidad a la experiencia de la verdadera religación del hombre, ya no con Dios sino con el ser.

\section{Conclusión}

De un modo u otro, el Kant de Heidegger finalmente parece enmascarar al propio Heidegger, en su inacabada tarea de fundamentación de la metafísica del Dasein. En otras palabras, la $\mathrm{CrP}$ debiera entenderse como una propedéutica para la analítica existenciaria de Ser y tiempo. Pensado así, el proyecto de una ontología existencial puede perfectamente ser acusado de anacrónico, si, como observa Dahlstrom (2011), entendiéramos el significado ordinario de anacronismo como "un error en el tiempo de cómputo", y, en tal sentido, presupusiéramos un concepto lineal del tiempo. Justamente de esto zafa la recepción heideggeriana de Kant y el problema de la metafísica, donde el tiempo, literalmente, se concibe como una protoestructura trascendental. ¿Qué significa en realidad esta afirmación? La crítica de Heidegger a Kant no pone en primer lugar el problema de la imaginación, y aunque parezca osado decirlo - al fin y al cabo, se trata en este escrito de sostener un pensamiento independiente-, ni siquiera el asunto del tiempo. Tal como lo presenta la misma conjetura, el tema fundamental de Kant y el problema de la metafísica es la articulación del binomio trascendental/trascendencia. Esto quiere decir, y probablemente este sea el mayor "descubrimiento" de Heidegger, que la analítica trascendental no sería otra cosa que una analítica de la subjetividad. De esta manera, Kant y el problema de la metafísica pasa a convertirse en "Heidegger y el problema de la trascendencia”, en el único sentido posible de lo que hemos llamado hasta acá concomitancia ontológica.

El joven Heidegger se ha propuesto realizar una hermenéutica de la analítica trascendental con el propósito de fundamentar su fenomenología del ser del ente. Y a la luz de los resultados de su texto sobre Kant, su logro está a la vista. Si el problema que pretendía dirimir la trascendencia era el de la constitución a priori de la objetividad, la interpretación de Heidegger parece exitosa. Por eso logrará decir que la formación de lo previo como tal, la pre-formación pura, es un acto de la imaginación pura. Si este acto, en el fuero filosófico interno de Kant, es en realidad voluntad o, dicho en los términos de Husserl, intencionalidad, es algo que, de cualquier forma, Kant no se atrevió a plantear. Tal como señala Carr (2007), el mérito de Heidegger es reconocer que en la deducción trascendental Kant duda entre la psicología y la lógica, porque no ve ninguna tercera alternativa, terminando por descartar su apego a la subjetividad, y optando por una versión lógica "al estilo escolástico”. Ante un reclamo tan lapidario como el de que "las intuiciones sin conceptos son 
ciegas" (Ferraris, 2013), es probable que el retroceso de Kant no haya sido ante el descubrimiento del fundamento, sino ante la posibilidad de una interpretación fenomenológica del mundo.

\section{Referencias}

Aldegani, E. (2016). Ontología y política. Análisis y observaciones de la filosofía de Cornelius Castoriadis. [Tesis doctoral]. Universidad Nacional de La Plata.

Barreto, S. (2012). Ontologia e Crítica da metafísica: Kant e Heidegger. Revista Estudos Filosóficos, 8, 18-32. https://tinyurl.com/yxnkhlng

Brandt, R. (2006). La cuarta crítica de Kant. Azafea, 8, 181-208. https://doi.org/10.14201/632

Carr, D. (2007). Heidegger on Kant on transcendence. En S. Crowell y J. Malpas (eds.), Transcendental Heidegger (pp. 28-42). Stanford University Press.

Castoriadis, C. (1999). Figuras de lo pensable. Cátedra.

Dahlstrom, D. (2011). Being at the beginning: Heidegger's interpretation og Heraclitus. En D. O. Dahlstrom (ed.), Interpreting Heidegger: critical essays (pp. 135155). Cambridge University Press.

Fayé, E. (2018). Heidegger. La introducción del nazismo en la filosofía. Akal.

Ferraris, M. (1999). La imaginación. Visor.

Ferraris, M. (2013). Goodbye, Kant! Suny Press.

Freudiger, J. (1996). Kants Schlußstein. Wie die Teleologie die Einheit der Vernunft stiftet [La piedra angular de Kant. Cómo la teleología crea la unidad de la razón]. Kant-Studien, 87(4), 423-435. 10.1515/ kant.1996.87.4.423

Garrido, J. J. (2019). La fuerza configuradora de la imaginación en el tiempo de la autoafección de la mismidad: Kant y Heidegger. Veritas, 43, 9-27. http:// dx.doi.org/10.4067/S0718-92732019000200009

Gómez-Sánchez, C. (2011). Sum moribundus versus sum trascendens: El debate sobre la conciencia en Heidegger y Kant. Daimon. Revista Internacional de Filosofía, 54, 149-166. https://tinyurl.com/y4pe5evr

Grondin, J. (2000). La actualidad de la religión dentro de los límites de la mera razón de Kant. Ideas y Valores, 49(113), 80-86. https://tinyurl.com/y3rth95u

Heidegger, M. (1991). GA 3. Kant und das Problem der Metaphysik. Fráncfort del Meno: Klostermann.

Heidegger, M. (1993). Kant y el problema de la metafísica. Fondo de Cultura Económica.
Heidegger, M. (1997). Ser y tiempo. Universitaria.

Heidegger, M. (2007). Principios metafísicos de la lógica. Síntesis.

Holguín de Torres, M. (1983). La interpretación heideggeriana del esquematismo en Kant. Ideas y Valores, 32(62), 81-99. https://tinyurl.com/yyzct65h

Kant, I. (1998). Crítica de la razón pura. Alfaguara.

Martínez Marzoa, F. (1987). Desconocida raíz común. Visor.

Martínez-Marzoa, F. (1999). Heidegger y su tiempo. Akal.

Martínez-Matías, P. (2018). Kant más allá de Kant: Heidegger y lo no-pensado de la filosofía kantiana. Con-Textos Kantianos, 7, 128-158. https://doi. org/10.5281/zenodo.1298712

Massey, H. (2015). The origin of time: Heidegger and Bergson. Suny Press.

Papadimitropoulos, V. (2020). The radical freedom of the imaginary in Castoriadis. Cosmos \& History, 16(1), 24-46. https://tinyurl.com/y5wz43vr

Pardon, L. (2015). La antropología como fundamento de la metafísica: la crítica de Heidegger en Kant y el problema de la metafísica. En X Jornadas de Investigación en Filosofía. Universidad Nacional de La Plata, 19 a 21 de agosto de 2015.

Pedrol, X. (2003). La filosofía política de Cornelius Castoriadis. [Tesis doctoral]. Universidad de Barcelona.

Poole, N. (2013). Kant, Heidegger and the problem of indifference: from reason to releasement. [Tesis de maestría]. University of British Columbia.

Rodríguez-Aramayo, R. (ed.). (1992). Crítica de la razón ucrónica. Estudios en torno a las aporías morales de Kant. Tecnos.

Schalow, F. (1994). The unique role of logic in the development of Heidegger's dialogue with Kant. Journal of the History of Philosophy, 32(1), 103-125. https:// tinyurl.com/y254hggs

Sicerone, D. (2017). La crítica de Žižek a la concepción del sujeto en clave historicista. Reflexiones Marginales, 42, 1-21. https://tinyurl.com/y4wgy8de

Sola, M. (2000). Trascendental y trascendencia en Heidegger. [Tesis doctoral]. Universidad de Sevilla.

Sola, M. (2002). La idea de lo trascendental en Heidegger. Kronos.

Stepanenko, P. (2005). Deducción trascendental de los conceptos puros del entendimiento. (Crítica de la 
Razón Pura, 1a. ed., A95-A130). Ideas y Valores, 127, 99-126. https://tinyurl.com/y3tpsb6z

Vargas, N. (2018). La interpretación fenomenológica de la "triple síntesis" de Kant en Kant y el problema de la metafísica de Martin Heidegger. Resonancias. Revista de Filosofía, 5, 30-48. 10.5354/0719-790X.52498
Villacañas, J. L. (1987). Racionalidad crítica. Introducción a la filosofía de Kant. Tecnos.

Žižek, S. (2001). El espinoso sujeto. Paidós. 